\title{
10
}

\section{Organizational Cultural Hybrids: Nonprofit and For-Profit Cultural \\ Influences in the Kenyan Technology Sector}

\author{
Eleanor R. Marchant
}

"When you look at the infrastructure here, we should be miles ahead. But there's so much fluff money, no hard talk, NGOs propping businesses up—it kills it."

- Nikolai Barnwell, in a Wired article by Jessica Hatcher, June 10, 2014

"Yes, my good people, I said it. It was NGO 'Aluff' money that funded what we do today."

— Sam Gichuru in a blog post, June 10, 2014

\section{Introduction}

Back in 2014, a debate swept through the Kenyan tech sector about the value of grant funding for start-ups based on new technology. Swirling around the blogosphere, among Kenyans on Twitter, and entrepreneurs in the thick of it, the debate seemed to boil down to the question of

E.R. Marchant $(\bowtie)$

University of Pennsylvania, Philadelphia, US

(C) The Author(s) 2017

B. Ndemo, T. Weiss (eds.), Digital Kenya,

DOI 10.1057/978-1-137-57878-5_10 
whether grants from nongovernmental organizations (NGOs) and donor organizations interested in funding social enterprises in Kenya were a benefit or a hindrance. Put in less secular terms, many asked: Is grant funding a blessing or a curse? Key figures, like Nikolai Barnwell, at that time the manager of the technology business incubator $88 \mathrm{mph},{ }^{1}$ and Sam Gichuru, the manager of Nailab (a competing tech incubator), landed on one side or the other of the debate. Even now, more than a year after the debate peaked in social media, its question still lingers over Kenyan entrepreneurs.

Seen through the lens of this debate, the presence of grant funding, or more generally the presence of nonprofit organizations, seems black and white. It is either good for the growth of the sector or it is not; it either spurs innovation or it does not. In this chapter, my goal is to take this debate and reframe it in more constructive, less binary terms. I hope to do this by introducing a new lens through which to look at technology companies in Kenya, the lens of cultural theory. I will use this lens to make the case that the future of Kenyan technology innovation lies in the mixing of nonprofit and for-profit cultures in the sector and not in a battle between the two.

By culture, I refer not to national or ethnic cultures, but to cultures understood more broadly as a set of beliefs, practices, and assumptions of a particular group, whether that group is based around an organization, a nation, or even around an idea. Looking just at the culture of organizations - for good or ill — the Kenyan tech sector is an exceedingly multicultural place. There are large international for-profit tech companies like IBM and Google; international and domestic investors like Savannah Fund, Emerging Capital Partners, and Impact Amplifier; aspiring Kenyans and other East Africans entrepreneurs; donor organizations like the World Bank, Omidyar Foundation, and Hivos Foundation; social enterprises; public-private partnerships; and countless others. For most researchers who study culture (and this group is large and disparate), culture is understood to rarely be stagnant. It is prone to change, to evolve over time (Runciman 2005), and to undergo hybridization, ${ }^{2}$ particularly in multicultural places (Kraidy 2005) like the Kenyan tech sector.

\footnotetext{
${ }^{1}$ In this chapter, I will refer to the organization as $88 \mathrm{mph}$, even though it has been renamed Nairobi Garage, because the name change occurred after most of the research for this chapter had been conducted.

${ }^{2}$ When speaking about culture, the term hybridization is typically used by academics to refer to the mixing of two separate cultural groups. A good example of this is the case of second-generation
} 
In this chapter, I look at nonprofit and for-profit organizations and approaches to the work of technology development as forms of organizational culture. If we accept that cultures adapt and change in the presence of one another, it becomes easier, more intuitive, to see how changing forms of work and organizational structures are a natural result of the Kenyan tech sector's multiculturalism.

In the remainder of this chapter, I will provide some background on the theories of organizational culture and cultural hybridity. I will lay out what, according to existing research, traditional nonprofit and for-profit organizational cultures look like, drawing in particular from Schein's theory of the levels of organizational culture (Schein 1990). I will use this picture to construct a typology of the two different types of organizational culture. I will then demonstrate how two individual organizations at the center of the Kenyan tech sector are cultural hybrids - whether that hybridity is intentional or not - that to varying extents adopt and adapt underlying cultural assumptions, espoused beliefs, and practices from both traditions.

The two organizations are the technology hub iHub and the technology incubator $88 \mathrm{mph} .^{3}$ As mentors to entrepreneurs, the incubators and tech hubs in Kenya act as role models for fledgling start-ups. Whether these start-ups are successful or not, the example that the incubators and hubs set through the cultural models they themselves adopt could have an influence on how aspiring entrepreneurs approach their work in the future and what future organizations in the industry look like. This is primarily a comparative case-study analysis; the data used in the chapter were drawn from ethnographic fieldwork conducted by the author in Nairobi in the summers of 2013 and 2014, predominantly at iHub but with site visits to and interviews conducted at $88 \mathrm{mph}$. Data are also

members of a diaspora group (e.g., Nigerian-Americans or Somalis living in London) who retain some of their home culture but adopt much of the cultural practices and even beliefs of their new host country as well.

${ }^{3}$ Small-business incubators are understood by management scholars to be organizations designed to accelerate the growth of entrepreneurial businesses. Frequently, they offer a physical space and an intense training program, as well as access to capital to help businesses grow. Tech hubs, while less clearly defined, are, like incubators, typically designed to nurture entrepreneurial businesses but in less formal ways. They typically provide communal space and focus on network building in order to foster the generation of new innovative ideas. They do not provide direct funding. 
drawn from an analysis of the discourse and rhetoric used by representatives of both organizations publicly and in interviews with the author.

The two organizations chosen are often seen as representing opposite sides of the nonprofit-for-profit debate in Kenya, because iHub was built initially on grant funding from nonprofit organizations, like the Omidyar Foundation, and $88 \mathrm{mph}$ was built initially by a pool of for-profit investors. By using these contrasting examples, I hope to demonstrate the different ways that cultural hybridity are manifesting within organizations in the sector. By using the method of in-depth case studies, I will explore some of the internal dilemmas that this hybridity causes and how these two organizations have managed it in very different ways.

The mixing of nonprofit and for-profit beliefs and practices gives the Kenyan tech sector access to more and different resources, resources that must be managed carefully and conscientiously. By looking closely at how existing organizations are managing this hybridity, my hope is that we can develop strategies for taking advantage of the multiculturalism that clearly exists in the Kenyan tech sector rather than fighting about whether it is good or bad.

\section{Theoretical Grounding}

\section{Organizational Culture}

When we think about the culture of an organization, somewhat vague but emotive concepts like "the way we do things around here" or "the way people interact with and treat one another" might come to mind. Scholars studying culture at organizations, particularly in the management field, have identified four different types of culture in and around organizations: (1) the cultural context (as in the national, geographic, or industrial cultures surrounding it), (2) cross-cutting cultures (as in the different occupational or ethnic cultures of its employees), (3) subcultures specific to the organization (as in the particular cultures of departments within the organization), and, and most important, for this chapter, and (4) organizational culture (the culture of the organization itself ) (Gregory 1983). These types of culture are all certainly worthy of 
greater investigation in the context of a multicultural environment like the Kenyan tech sector, but it is organizational culture that we are primarily concerned with here.

Andrew Pettigrew, widely considered to be the grandfather of the study of organizational culture, provided a definition that began to clarify what the culture of an organization was. He defined it as an amalgamation of beliefs, identity, ritual, and myths (Pettigrew 1979) of an organization. This definition, and in particular, the inclusion of the themes of beliefs and rituals, has greatly influenced those studying organizations, including prominent scholars like Geert Hofstede and those studying technology organizations, like Kathleen Gregory. In the 1990s, Edgar Schein, a professor at MIT's Sloan School of Management, built on Pettigrew's definition and constructed a useful framework for analyzing and identifying organizational culture. This framework is known as the three levels of organizational culture and includes: (1) basic underlying unspoken assumptions, (2) espoused beliefs and values, and (3) visible artifacts and behaviors (Schein 1990). Within each of these levels, Schein found important evidence of an organization's culture, though each level required a different method of research (e.g., analysis, interviews, and observations).

At the first level, the underlying assumptions often reside in large-scale ideological, philosophical, or theological commitments; they are basic assumptions about how the world is, or more often the case, how it ought to be. Such commitments could be to a particular religion, for example, or to democracy, neoliberalism, capitalism, and so on. Because assumptions are just that - things that are assumed or taken for granted-they can be the most difficult for researchers to pin down and require deep analysis. Yet, according to Schein, they are fundamental to how much of the rest of an organization's culture is determined.

At the second level, the espoused beliefs and values are the views, articulated by members of an organization, that guide its purpose and its structure. This level has received the most attention from scholars, because it is typically relatively easy to identify through interviews or in an organization's manifestos and policy statements. Yet the beliefs and values are often greatly shaped by the ideological commitments and assumptions of the first, and more elusive, level of underlying assumptions. 
And at the third level, the behaviors are the manners and customs of interaction between different individuals and departments at an organization or how the organization behaves externally. And the artifacts are, according to Schein, "everything from the physical layout, the dress code, the manner in which people address each other, the smell and feel of the place, its emotional intensity, and other phenomena, to more permanent archival manifestations such as company records, products, statements of philosophy, and annual reports" (Schein 1990). In short, the artifacts are the material aspects of an organization's culture and are typically understood through direct observation.

Finally, an important part of Schein's characterization of culture at organizations is that these three levels are not absolutely distinct; they feed into one another and comprise a more organic and ongoing process than the term "levels" can convey (Schein 2010). Underlying assumptions motivate, consciously or not, the central goals of an organization or the motivations of individuals for working there. And in turn, the organization's core values and beliefs influence how they choose to structure themselves and how everyday operations take place (Greenwood and Hinings 1993). Google, for example, maintains an open-plan office and gives its employees time to work on their own projects (representing the artifacts of the third level) because of the espoused belief that such structural factors encourage more innovation and because of the underlying assumption that innovation is good for society. This interrelationship between the various levels of culture is an important part of Schein's framework and helps to visualize organizations as the organic fluctuating entities that they are.

\section{Organizational Hybrids}

The conceptualization in Schein's model of organizational culture as organic and fluid is in keeping with a wider body of scholarship about culture and change. Scholars in cultural studies frequently describe culture as constantly evolving and being prone to hybridization, adaptation, and change in a myriad of ways (Gillespie 2010; Kraidy 2005). The evolution of Sheng, the rich and unstructured linguistic hybrid of Kiswahili 
and English used in Nairobi, is an example of a hybrid cultural artifact that emerged out of the close quarters in the city that brought many different linguistic cultures into contact with one another. For scholars of organizations, hybrids are organizations that cross sectorial or institutional boundaries or use core beliefs and practices from multiple organizational types (Doherty et al. 2014; Mangen and Brivot 2014). A social enterprise is the quintessential example of a hybrid organization because it has both a social-impact purpose and a drive for financial sustainability (Doherty et al. 2014), meaning that it is motivated by core beliefs from two different sectors, the nonprofit and the for-profit sectors.

A prominent debate among researchers of organizations is whether hybrid organizations are stable and sustainable. For example, Greenwood and Hinings (1993) have argued that organizations tend to move toward a single set of core values and beliefs because of the internal conflict caused by the presence of multiple potentially incompatible beliefs. This view of hybrid organizations as inherently unstable dominates the existing literature on organizations. However, more recent research carried out in countries in the Global South has provided evidence that hybrid organizations may actually be well suited to such environments. In Bolivia, Battilana and Dorado (2010) demonstrated that new organizations that began as some kind of hybrid, like a social enterprise, had greater potential for sustainability than more established organizations seeking to change their organizational culture. For social enterprises in two different African countries, Gupta et al. (2015) made the case that hybrid organizations may actually be useful in resource-constrained environments.

By combining the theories of organizational culture and hybrids described above, I believe it is possible to attain a more holistic and nuanced sense of the construction of hybrid organizations that goes beyond the core beliefs typically examined. In the rest of this chapter, I use Schein's framework of the levels of organizational culture: (1) to identify organizational culture at traditional nonprofit and for-profit organizations and (2) to examine how iHub and $88 \mathrm{mph}$, two organizations in the Kenyan technology sector, are to varying extents organizational cultural hybrids that have adopted beliefs, practices, and even assumptions from both traditional nonprofit and for-profit organizational cultures. 


\section{Nonprofit and For-Profit Organizational Cultures}

At a basic level, the difference between nonprofit and for-profit organizations may seem self-evident, even tautological—one has the goal of generating profit, and one does not. Right? Going back to the original debate about what is good for the Kenyan technology sector, these two have certainly been painted as contrasting, even oppositional, types. A brief return to the literature here, using Schein's levels of organizational culture, will help provide a more holistic and nuanced view.

Most of the research on organizational culture has been done by management scholars and has focused predominantly on culture at for-profits. The research was typically of the overarching variety, working to build generalized theories that might explain or predict organizational behavior as a whole across many varied organizations. The majority of these studies also focused exclusively on for-profit companies and often on the role of leadership in encouraging the growth of a "strong" organizational culture (Bass and Avolio 1993; Clement 1994; Ogbonna and Harris 2000). However, there have also been a number of narrower studies looking at the particular iterations of organizational culture in unique types of organizations, like family-run manufacturing firms in the USA (Zahra 2003), Japanese firms (Deshpandé et al. 1993), multinational companies (Jaeger 1983), service sector companies (Chatman and Jehn 1994), and Silicon Valley companies (Gregory 1983), among many others.

There have been fewer studies looking at the concept of organizational culture in the particular context of nonprofit organizations. Tierney's study (1988) of higher education institutions is one such example, as is Murta's study (2011) of a nonprofit organization in El Paso, Texas. Many of these studies were intended to advise nonprofits on how to build a more efficient and innovative organizational culture resembling those with the strength that many researchers see in the culture of for-profit organizations (Dartington 1998; Lindenberg 2001). Similarly, although they do not refer specifically to organizational culture, recent studies by Hwang and Powell as well as Watkins and colleagues have addressed many of the cultural elements of nonprofits, including levels of professionalism 
(Hwang and Powell 2009) in the nonprofit sector in San Francisco and the organizational goals and material technology employed by international development NGOs (Watkins et al. 2012).

A handful of studies have looked comparatively at aspects of culture of nonprofit and for-profit organizations. One such study was conducted by Hull and Lio (2006) of the Rochester Institute of Technology in New York. They outlined the ways in which cultures differed between the two organizations. They broke down these differences into three core components of the organization: vision, strategic constraints, and financial constraints. Other scholars, like Billis (2010), have contrasted forprofit and nonprofit organizations as follows: private-sector organizations are determined by their market orientation to maximize financial return, with ownership by shareholders and a revenue model based on sales and fees, whereas nonprofit-sector organizations are determined by their social and environmental goals, with ownership by members and the private election of representatives, staffing by a combination of employees and volunteers, and a revenue model based on membership fees, donations, and legacies (Billis 2010).

Table 10.1 uses the information acquired from the studies of culture at nonprofit and for-profit organizations described above and fits it into Schein's levels of organizational culture framework, thus creating a typology of the organizational culture of traditional nonprofit and for-profit organizations.

The first level, that of underlying assumptions, is rarely covered in the literature. As a result, the table draws from underlying assumptions embedded in the literature itself and findings from the author's own ethnographic fieldwork. Underlying assumptions includes an organization's underlying priorities in society and ideological commitments. The second level, that of espoused beliefs and values, has received the most attention from researchers and thus is the most comprehensively represented of the three levels. It includes an organization's goals, scope of impact on society, and grounding in society. Finally, the third level, that observed artifacts and behaviors, includes an organization's strategies for revenue generation, who an organization is responsible to, and an organization's ownership structure. However, it excludes a number of more specific elements of artifacts, such as an organization's layout or the habits of interaction between various departments, 
Table 10.1 Organizational culture at traditional nonprofits and for-profits

Levels of organizational Categories of organizational culture culture For-profits Nonprofits

\section{Underlying assumptions}

$\begin{array}{cll}\begin{array}{c}\text { Underlying societal } \\ \text { level priorities }\end{array} & \text { Economic growth } & \begin{array}{l}\text { Equality and empowerment } \\ \text { of disadvantaged }\end{array} \\ \begin{array}{c}\text { Ideological } \\ \text { commitments }\end{array} & \text { Free market economy } & \text { Philanthropic economy }\end{array}$

\section{Espoused beliefs and values}

Goal/vision

Scope of societal impact

Geographical grounding
Revolves around how to maximize profits while providing the services they are designed for
To maximize positive social change; vision forms core of organization's work

Societal impact considered Seeking to bring about to the extent that it social change in society affects profit generation Flexible, able to relocate, Committed to the or expand of necessary for location(s) in which they profit operate

\section{Observed artifacts and behaviors}

Ownership structure

Responsible to

Revenue generation
Shareholders

Shareholders and, to a lesser extent, employees

Seeks revenue maximization through sales and fees
Donor support, members

Donors, employees, volunteers, intended beneficiaries

Donor support, project revenue goes to improving service

in order to focus on the most salient categories for understanding the differences between nonprofit and for-profit organizational cultures.

Although this composite may seem a tad cumbersome, I believe it to be a worthwhile improvement over existing literature, which rarely looks at organizational culture holistically and instead focuses more narrowly on the level of beliefs and values or solely at an organization's structures.

The core differences between nonprofit and for-profit organizational cultures as outlined here originate at the base level of underlying assumptions. The assumptions about what is good for society and what kind of socioeconomic system is best seem to stand in stark contrast with one another. For-profits typically rely on an ideological commitment to the 
free-market economy, where the logic of the market is the best way to build a better, more economically prosperous world. By contrast, nonprofit companies are typically built on the assumption that the market is not enough — that there are important aspects of the social world that the financial markets are not designed to improve or support, such as poverty eradication or social welfare.

These contrasting underlying assumptions and ideological commitments trickle down to influence the culture of an organization at the other two levels. At the level of espoused beliefs and values, for example, the goals of a typical for-profit revolve around the maximization of profits, driven by the belief in the free-market system. Even when there is a strong commitment to the particular service being provided (for example, a great search engine or the best mobile taxi application), it is believed that the service cannot be provided sustainably without a profit-driven revenue model. By contrast, the assumption that some social problems cannot be addressed within a free-market system drives nonprofit organizations to put the goal of maximizing positive social change at the forefront.

In turn, both the underlying assumptions and the core beliefs influence the behavior and artifacts of an organization. For the typical forprofit, for example, their stakeholders are largely made up of shareholders (and to a lesser extent, other individuals such as clients), whereas for the typical nonprofit, a large and diverse array of individuals must be kept in mind, ranging from the intended beneficiaries of the nonprofit's socialimpact work to the donors who support it and the individuals who give their time freely or for reduced pay.

\section{Case Studies: iHUB and 88MPH}

In this section, I use the two contrasting typologies of organizational culture outlined above to illustrate that two key organizations in the Kenyan technology sector, the incubator $88 \mathrm{mph}$ and the technology hub iHub, are hybrids of the two cultures and that the hybridity of organizational culture can take quite different forms.

The incubator and hub were chosen for this study because, as nurturers of emerging companies, they are potentially serving as cultural models 
for the organizations they are helping to build and for the individuals they are helping to train. I chose $88 \mathrm{mph}$ and iHub for the specific case studies to illustrate Kenya's incubators and tech hubs. iHub has been described as the first tech hub in Africa, and its role as a trendsetter makes it an important illustrative choice. $88 \mathrm{mph}$ (now called Nairobi Garage) is a start-up incubator that adopted a for-profit model popular in Silicon Valley at the time it originally opened in Nairobi. There are a fair number of other incubators and hubs in Kenya, but, as I will demonstrate, iHub and $88 \mathrm{mph}$ serve as useful points of comparison when the topic of interest is the hybridity of nonprofit and for-profit organizational culture.

\section{Artifacts and Behaviors}

Beginning with the typologies associated with the third level of organizational culture, artifacts and behaviors (Table 10.1), iHub largely aligns with the nonprofits and $88 \mathrm{mph}$ with the for-profits. In terms of ownership structure, iHub was originally founded by Erik Hersman and Juliana Rotich, part of the team that made the software company Ushahidi famous. iHub received initial financial support from donor organizations, such as the Omidyar Network and Hivos Foundation, and is guided by a dedicated local advisory board that includes Bitange Ndemo, the former permanent secretary of Kenya's Ministry of Information and Communication, and Becky Wanjiku, the Kenyan chief executive officer (CEO) of Fireside Communications Limited. iHub's business model at this point relies on partnerships with Internet providers (e.g., Zuku and Safaricom) that have supplied iHub with free Wi-Fi access to help nurture the sector and on international tech companies, like IBM, Microsoft, and Google, that helped finance many of iHub's popular events, including networking events and trainings from experts. Its model of revenue generation has been based mostly on hosting these kinds of events in its large, open-plan space (akin to a Google-style space) on financing from donors, membership dues collected from developers and techies who use the space, and conducting paid research. iHub has been able to keep some of its expenses down through many of its partnerships (e.g., the free Wi-Fi supplied by partners). 
As in the case of traditional nonprofits, to whom iHub is responsible is not straightforward, but it is clear from interviews and observations that the core of its commitment is to a community grounded in Nairobi. In an interview, Hersman illustrated the integral role he believes members of the community have played in the origins of $\mathrm{iHub}$ and in sustaining its continued success, saying, "Even before there was a space we had an advisory board of people from the community. So we actually knew people from that community. We're part of that community, so it's easier. ... Before we even had any paint on the wall, we had dozens of volunteers" (Duarte 2012).

The meaning of community espoused by Hersman and most prevalent among members of iHub has many layers. It seems first and foremost to be a community of techies and developers who use the space to work on their businesses, but more broadly, it can be seen as the many varied individuals who have dedicated themselves to the idea of strengthening the iHub community and strengthening the ability of Kenya to become a hub for tech innovation in Africa. This community includes organizations and individuals from outside of Kenya who have a genuine interest in supporting the growth of the sector in one way or another, including its funders and its many numerous partners. In short, iHub's commitment seems to be to the success of the community.

The behavior and structure of $88 \mathrm{mph}$ is more in line with the for-profit typology. Founded by a European serial entrepreneur, Kresten Buch, who came out of Stanford Business School in the USA, $88 \mathrm{mph}$ describes itself on its website as a seed fund that invests in, and connects investors to, particular start-ups nurtured during a three-month accelerator program. It resembles in many ways the incubator programs in Silicon Valley, like Y-Combinator, that provide intensive training and mentorship during their accelerator programs and connect successful entrepreneurs to potential investors. The key employees at $88 \mathrm{mph}$ are also shareholders, encouraging a sense of personal stake in ensuring these start-ups grow and profit. When it first opened, Buch and many of $88 \mathrm{mph}$ 's initiating staff were new to the Kenyan context and most of their investors were foreigners. Over the next few years, they worked to engage more with local actors, and by 2012, 11 of their 17 investors were from East Africa. $88 \mathrm{mph}$ has currently put its accelerator program on hold while it focuses on its existing start-ups rather than diversifying with new ones. 
But they still maintain a group of "entrepreneurs in residence" from countries around the world who are intended to serve as mentors for the new entrepreneurs in Nairobi and at its other, newer offices in Cape Town and Lagos. As a for-profit company, $88 \mathrm{mph}$ 's model for revenue generation (see Table 10.1) is to invest in the very early-stage start-ups it mentors, including taking 7 percent equity in the fledgling companies. As Buch said in 2012, "The only way we can make money is if the startup does really well” (CNBC Africa 2012). The company conforms to the model of the majority of incubators in Silicon Valley, that is, for-profit at its core and incorporating the potential for high risk in the short term in the hopes of a high return in the long term.

Again, in keeping with the traditional model of incubators and accelerator programs around the world and with the for-profit typology shown in Table $10.1,88 \mathrm{mph}$ is primarily responsible to the investors who have supported it and who have invested in the start-ups. It also has a second responsibility to help the start-ups build financially successful companies, which feeds back into the goal of helping investors get a return on their investment. $88 \mathrm{mph}$ has made a point of bringing in Kenyan investors; the start-ups it nurtures in its Nairobi office are led by Kenyan or East African entrepreneurs, as well as a handful of foreign-led endeavors. Nonetheless, $88 \mathrm{mph}$ is not as embedded in the local Nairobi context as is iHub, which is particularly apparent through the multiple offices it has in Africa and in the level of espoused belief in wanting to "invest in technologies that solve problems for emerging markets" (CNBC Africa 2012).

\section{Espoused Beliefs and Underlying Assumptions}

The two organizations begin to overlap in notable ways when we look at the organizational culture embedded in their espoused beliefs and underlying assumptions, the second level of Schein's framework (see Table 10.1). As noted above, in the area of geographic grounding, they remain quite distinct. iHub has a clear commitment to growing the tech sector specifically in Nairobi and is highly integrated into that location, whereas $88 \mathrm{mph}$ is more flexible and could shift its attention to another 
office, like the one in Lagos, if the potential for a higher return on investment seemed more likely. That said, the involvement of local Kenyan and East African investors in $88 \mathrm{mph}$ projects means that many of the individuals in the organization now have a geographic commitment to Kenya. As Buch has said, "We need to understand the local market, so having local people come to advise and local investors is very important. We want to build those partnerships" (CNBC Africa 2012). Beyond the geographic relationship, it is in the other aspects of organizational culture at the level of beliefs and values as well as at the level of the core underlying assumptions that we see the original distinctions between nonprofits and for-profits begin to break down in iHub and $88 \mathrm{mph}$ and their organizational culture hybridize.

iHub still fits within the nonprofit type to a large extent within the level of espoused beliefs. Its members frequently use the language of positive social change when talking about iHub's goal of supporting the growth of the local technology community and locally designed technology in Kenya. More specifically, a number of the projects it helps to nurture and support also have clear social-impact objectives, like AkiraChix, which trains women to use technology and to program, or like the startup M-Farm, which nurtures growth in the agricultural sector by bringing market price information to farmers. Nonetheless, it is notable that while its own financial model is nonprofit, many of the organizations that have emerged from the iHub space are for-profit companies, some of which have built products that target the business-to-business marketin which nonprofit organizations have rarely been involved. Moreover, on its website, iHub describes one of its goals as creating "the place where seeds are planted and are easily found by the people with the money to help them grow." This mix of for-profit and nonprofit actors and funders is something that $\mathrm{iHub}$ has actively nurtured and that its leaders actively espouse. For example, in a 2014 post on his blog, WhiteAfrican, Hersman wrote clearly defending the role that nonprofit grant funding has played in supporting early-stage development in the Kenyan technology sector (Hersman 2014). But he has also emphasized his belief that many private companies see a "real viable opportunity" in the start-up ecosystem around the iHub space (Design Indaba 2014). Herman's choice to highlight the role of private companies as well as nonprofit organizations in 
his public interviews demonstrates the belief that iHub's mission is not exclusively a nonprofit one.

This goal of supporting the growth of a private sector, albeit a sector that the iHub team believes has the potential to affect social change, is atypical compared with traditional nonprofit organizational culture. It speaks to the important ways in which iHub diverges from the nonprofit type at the level of underlying assumptions (Table 10.1). iHub does resemble the nonprofit type in assuming that the work it is doing will help to empower the disadvantaged and reduce inequality. Where it differs is in its ideological commitment to building a successful and sustainable market economy for technology in Kenya. Many of its individual staff members, including its founders, appear to believe that nonprofit involvement has an important role to play in the early stages of the growth of the sector and of start-ups, but the belief that underlies this is that the growth of a for-profit tech sector can affect positive social change. At this base level of organizational culture, iHub represents a real hybridization of the characteristically for-profit commitment to the free market economy and the nonprofit commitment to philanthropic intervention where needed.

In the case of $88 \mathrm{mph}$, the typology at the level of underlying assumptions (see Table 10.1) is less ambiguous than for iHub. There is a clear underlying commitment to a free-market economy and profit generation akin to the typical for-profit. The way it measure its impact, for example, is a "pure, simple, bottom-line kind of investment" with "really no other impact metrics" (Barnwell 2014). At times, members of $88 \mathrm{mph}$ have been outspoken critics of the reliance on nonprofit grant funding in the sector (Hatcher 2014). In a 2014 interview with The Ideal Space, Nikolai Barnwell, then the manager of the $88 \mathrm{mph}$ Nairobi office, described his vision of where he wanted to see $88 \mathrm{mph}$ in the future, summing up up how the organization's commitments to profit and to a free-market economy have translated to the goals that its employees espouse. "In a few years," Barnwell said, "hopefully we will have invested in 100 start-ups across the continent, helped people make some cool start-ups, and our investors have made a lot of money" (Njiru 2014). These goals of creating "cool" technology as well as creating wealth resemble those of many in the tech sector in Silicon Valley. Members of $88 \mathrm{mph}$ have also articulated a desire to stay away from purely 
social enterprises because they perceive them as "easily dismissed as things around NGOs which are largely ineffective" (Barnwell 2014), a perception that appears to be drawn from an underlying belief that social enterprises are unlikely to lead to any profitable return on investment, in keeping with the assumptions of the for-profit typology.

Nonetheless, there are subtle ways in which social impact has crept into some of the language, or the espoused beliefs (see Table 10.1), used by individuals at $88 \mathrm{mph}$. In describing his own motivation, Buch explained, "I would love to work with people who really want to change the world. Who want to leave the nice corporate job and go down in salary to try to solve a problem" (CNBC Africa 2012). This language of "changing the world" is typical of that employed by many for-profit start-ups and incubators in Silicon Valley, where each is trying to prove that theirs is the next big idea that will change the world and therefore is deserving of support from investors. Nonetheless, $88 \mathrm{mph}$ 's decision to focus on the emerging economies of African countries seems to go beyond the work of "changing the world" that many in the American tech sector believe they are doing by creating the next dating app or smart watch. Although employees at $88 \mathrm{mph}$ still readily admit that profit generation for their investors is their primary goal, local job creation and regional economic growth are side effects that they routinely acknowledge or even highlight.

For example, when speaking with me, Barnwell acknowledged that while their primary goal is supporting the growth of their start-ups, ideally all of the people those start-ups hire "will be locally located so that it builds jobs" (Barnwell 2014). Local job creation was, in fact, the most frequently cited of the company's impacts beyond profit generation. Even if $88 \mathrm{mph}$ employees shy away from or even criticize the term "social impact" (Mulupi 2012), there is some acknowledgment of the potential for $88 \mathrm{mph}$ 's work to have a wider economic impact. And although many for-profit companies are highlighting these kinds of positive externalities, particularly with the rise of the corporate social-responsibility movement, it shows how social-impact language has begun to influence the beliefs that for-profit incubators in this sector, like $88 \mathrm{mph}$, are articulating.

The following figures depict the differences between the two cultural typologies as a continuum for assumptions, beliefs, and artifacts, representing each level of organizational culture described in Table 10.1. 


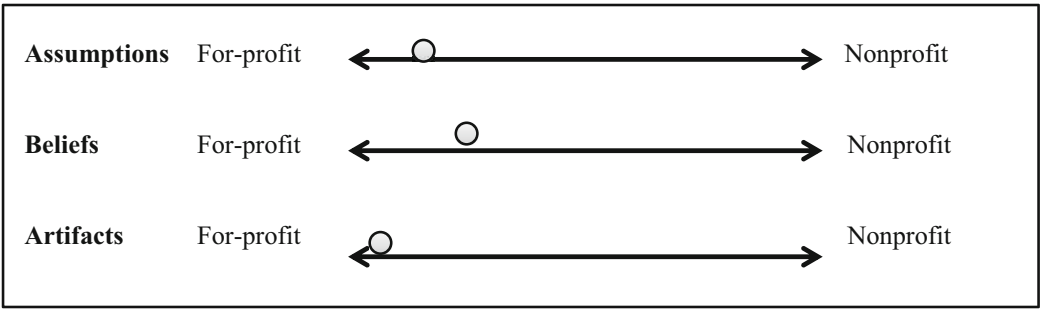

Fig. $10.188 \mathrm{mph}$

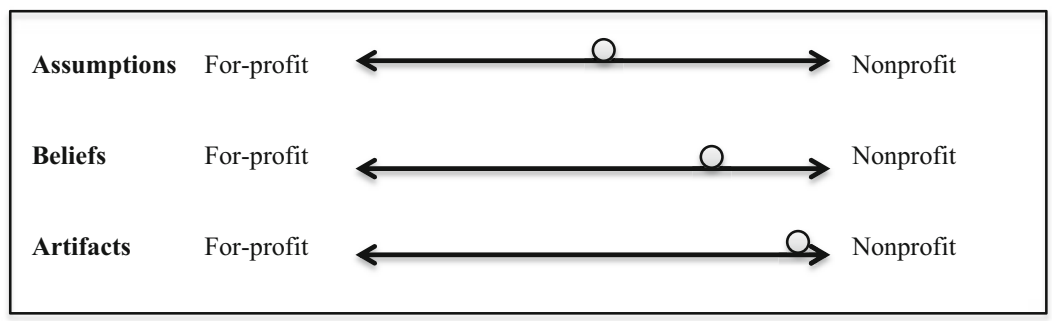

Fig. 10.2 iHub

Based on the above analysis, I have placed iHub and $88 \mathrm{mph}$ on these continuums. The figures certainly oversimplify the cultural complexities at both of these organizations, and the positions chosen for them are not hard and fast. Rather, the figures are simply intended to illustrate that although both of these organizations are hybrids, their hybridity takes very different forms (Figs. 10.1 and 10.2).

At the level of behaviors, iHub's structure makes it responsible to a wide array of actors in the community to which it is committed, while $88 \mathrm{mph}$ 's primary responsibility is to its investors. At the level of beliefs, they share the goal of supporting the growth of tech start-ups in Kenya, though iHub's motivation for that seems to revolve more around the social impact of such growth while $88 \mathrm{mph}$ ' lies more in the generation of profit and perhaps also regional economic growth and job creation. And at the level of assumptions, they seem to have more in common with a mutual, unspoken commitment to the growth of a free-market economy around the Kenyan tech sector, a notable area where iHub seems to diverge from the nonprofit typology. 
With such a diverse array of organizations present in the Kenyan tech sector, $88 \mathrm{mph}$ and iHub are exposed to many organizations that they might draw on for inspiration. In the globally connected ecosystem of the technology sector, they are also connected to organizational cultures from beyond Kenya, including the organizational culture of Silicon Valley to name but one. It may be that some hybrid composite of nonprofit and for-profit organizational culture, combined with some of these other organizational cultures (e.g., Silicon Valley tech culture or Kenyan business culture) not explored in this chapter, may become the norm for the Kenyan tech sector. I believe it is still too early to say. What can be deduced at this stage, I suggest, is simply that these two organizations have decided that adopting cultural beliefs and practices from at least two different organizational cultural types is the best way for them to operate in the current Kenyan tech sector.

\section{Conclusion}

In this chapter, I have made the case that in order for progress to take place in the Kenyan technology sector, we need to move beyond the stale debate about whether nonprofit grant funding is good or bad and instead find ways to take advantage of the multiculturalism that exists in the sector. In order to do this, I have drawn on existing theories about culture at organizations to demonstrate that even organizations like $88 \mathrm{mph}$, often associated with the for-profit model that dominates the discourse, are not purely for-profit when they are examined more holistically using the lens of cultural theory. By using Schein's theory of the three levels of organizational culture-underlying assumptions, espoused beliefs and values, and observed artifacts and behaviors-I have demonstrated in a more nuanced way that cultural hybridity exists at key organizations in Kenya's technology sector and that the practices and behaviors of these organizations are shaped by their fundamental underlying assumptions.

The cultural reality at iHub and $88 \mathrm{mph}$ is certainly even more complex and more fluid than was presented in this chapter. Organizations are essentially living ecosystems; they have many individuals within them who maintain various kinds of relationships across individuals, 
departments, job descriptions, and time. They are also, like the hybrid language Sheng, continuously evolving and adopting to different contexts, needs, and beliefs. The goal of this chapter was not to paint a comprehensive picture of all of the cultural influences at $88 \mathrm{mph}$ and iHub but to illustrate that these organizations are more complex than their revenue models might suggest.

\section{Implications}

\section{For Kenya}

Acceptance of this hybridization could have important implications for the future of technology companies in Kenya. A more hybridized organizational culture at the incubators and hubs_-organizations that nurture the newly emerging technology start-ups of Kenya-could lead to more hybridity in the organizational culture at the start-ups themselves. In a sector that is riding on the potential of such start-ups to build the country's future tech industry, the choices that entrepreneurs and start-up managers make about organizational culture early on could have the potential to influence the growth of this promising industry. Accepting that this hybridity already exists is a key step in findings ways to take advantage of it and to work with it creatively and conscientiously.

\section{Beyond Kenya}

I would argue that the intermingling of nonprofit and for-profit culture observed at iHub and $88 \mathrm{mph}$ is reflective of larger trends of overlap between these two sectors, not only in Kenya, but also in other parts of African and the Global South. Public-private partnerships, microfinance for development, and social-impact investing have all been growing trends over the last 15 years in many countries in the Global South. In countries like Kenya, Nigeria, and Ghana, not only are nonprofits and international donors investing in start-ups, something that 
would have been hard to find five or ten years ago, but they are also adopting some of the language, and perhaps even the beliefs, of the forprofit sector. This may be seen in a focus on "sustainability," "agribusiness," or testing new "business models," like the World Bank's infoDev project, or in committing to "sustainable economic development" as a core pillar of an organization's work, as Hivos Foundation has done. Similarly, in ways akin to the experience of $88 \mathrm{mph}$, many for-profits operating in Kenya and other parts of Africa have begun adopting some of the more social-impact-focused goals and visions typically associated with nonprofits into the language they use to explain their work. Multinationals are particularly good examples of this, with some, including IBM, Google, and Microsoft, frequently articulating a desire to help "build local capacity" in Africa, as in IBM's commitment to "encourage[ing] and strengthen[ing] an innovation culture" in its work in Kenya (citizen IBM 2012).

Furthermore, the review of the theories of organizational culture and hybridity provided in this chapter illustrated the existing literature's weakness at explaining the behavior and structure of new organizations in emerging economies in the Global South and particularly the role of hybrid organizations in these spaces. The existing literature, largely built from studies in the USA and Europe, sees hybrid organizations as inherently unstable. Work from scholars like Battilana, Gupta, and their colleagues, as well as the case studies provided here, provides early indications that the opposite might in fact be true in countries in the Global South, or at the very least that such hybridity is a potentially more natural part of the development of economies in the Global South.

\section{Recommendations for Practitioners}

I want to offer a few recommendations for practitioners working in the Kenyan tech sector and in technology innovation in multicultural environments in general that have come out of the research conducted for this chapter. These recommendatons are: (1) to embrace hybridity, (2) to think holistically about culture at an organization, and (3) to consider hybrid individuals for employment. 


\section{Embrace Hybridity}

In multicultural environments, I would recommend embracing the hybridity that multiculturalism might lead to, but be well-informed about the different kinds of culture that are influencing your work. Are you located in a cultural environment very different from the ones in which you have worked before? Perhaps in such environments it makes sense to adopt some of the cultural practices of the new environment into your organizational culture even if such practices have not been a part of your operations in other environments. Thinking about these practices as an element of fluid, evolving culture helps to embrace such hybridity and change over time as a natural part of organizations. Are there different cultural groups within your organizations that are creating divisions? One reason hybrid organizations are often believed to be unstable is that the hybridity is a result of the attempt to mix different cultural groups in one organization, which often leads to conflict between the groups. Such cultural mixing does not necessarily need to be avoided, but communication between such groups should be proactively managed.

\section{Think Holistically}

I would also recommend thinking holistically about the culture at an organization beyond just the choice of revenue model and to embrace the fluidity that comes with looking at culture and not just at the structure of one's organization. Although the debate about whether to accept grant funding or venture capital funding is very much alive among entrepreneurs in Kenya, it focuses on a small piece of the puzzle. Entrepreneurs should consider very carefully the choices they make about not just their revenue model, but also the myriad other aspects of organizational culture that they adopt. When designing the structure of a new company, what templates are being used to influence it? Incubators? Peer competitors? Successful foreign companies? If the latter, how different is the market those companies succeeded in from the one you are in? Purposeful, conscientious attention to understanding why particular elements of culture are being adopted could go a long way to helping fledgling organizations 
stay committed to their goals and retain a sense of organizational coherence even when adopting cultural practices from multiple different organizational cultures.

\section{Consider Hybrid Individuals}

Once the cultural hybridity in a multicultural sector is embraced, it becomes easier to develop tangible strategies for managing an organization's cultural hybridity, such as hiring hybrid individuals. There is some evidence from the literature that hybrid individuals — individuals who have experience working in more than one kind of organizational culture-are particularly adept at switching between the two cultures or combining them. Think, for example, of individuals with dual nationality and experience living in two or more countries. They are typically able to adapt and blend into each country far more easily than a foreigner who might have to learn a new language or who might falter on even such basic things as the appropriate way to greet an elder. In their work in Bolivia, Battilana and Dorado (2010) demonstrated that new hybrid organizations benefitted from hiring employees with experience in the various cultures that the new organizations represented. Much more research needs to be carried out in order to better understand the roles these individuals might play, but the potential for hybrid individuals within hybrid organizations is one way in which embracing hybridity can have practical consequences.

\section{Recommendations for Researchers}

Finally, one of the goals of this chapter was to lay the groundwork for research on culture and organizations in technology sectors in African economies. Recommendations for avenues of research in this area include: (1) examining the stability or sustainability of organizations with hybrid cultures in the sector, (2) studying the ways in which the culture of organizations in the sector are changing over time, (3) problematizing the influence of other forms of culture at organizations (e.g., the cultural 
context, cross-cutting culture, and sub-culture), (4) deconstructing the meaning of the culture for an organization's employees, and (5) testing the applicability of theories of intercultural communication to hybrid forms of work.

Such research could help build a more holistic picture by looking, for example, at the change in organizational culture at incubators and hubs over time or at how individuals inside and outside of them construct or perceive their cultural influences. Watkins et al. (2012) have argued that "NGOs are shaped as much by how they are imagined as by what they actually do." How do start-up managers perceive the incubators and tech hubs? How would members of an organization's advisory board characterize it? How might this characterization change depending on whom they are talking to?

Closer examination of the relationship between these organizations and the industrial and cultural context in which they exist could also prove very fruitful. Do the incubators and tech hubs in Kenya, as I speculate in this chapter, really have any power to shape the organizational cultures of the start-ups they work with or the institutional norms being adopted by the country's tech industry as a whole? Is there something theoretically useful to be learned from studying organizations forming in new industries like the Kenyan tech industry that might be applicable more broadly?

Finally, I believe that the study of intercultural communication could provide a particularly fruitful avenue for research on these kinds of hybrid organizational cultures in multicultural environments. Researchers specializing in intercultural communication have typically focused on environments with a mix of national cultures, like foreign language classrooms or among students who study abroad. By taking some of the theories that were developed in these contexts-like cross-cultural competence, cultural intelligence, or code-switching - and applying them to the study of culture at organizations, researchers could help in a number of ways. They could build theory about how hybrid organizations interact with one another or with nonhybrid organizations or test the value of hiring hybrid employees with experience working in various different organizational cultural environments.

Nonprofit, for-profit, and hybrid organizations are likely to be part of Kenya's tech sector for a while. And as in any environment where cultural 
groups are forced to live together, there is the potential for conflict. It is my hope that highlighting the areas in which these organizational groups overlap culturally and drawing attention to the fluidity of culture, as this chapter has done, will help individuals in the sector acknowledge the areas of common ground between them and to use them to facilitate easier communication during the many intercultural interactions that take place on a daily basis in this diverse sector.

\section{References}

Barnwell, N. (2014). Eleanor Marchant interview with Nikolai Barnwell.

Bass, B. M., \& Avolio, B. J. (1993). Transformational leadership and organizational culture. Public Administration Quarterly, 17(1), 112-121.

Battilana, J., \& Dorado, S. (2010). Building sustainable hybrid organizations: The case of commercial microfinance organizations. Academy of Management Journal, 53(6), 1419-1440.

Billis, D. (2010). Hybrid organizations and the third sector. Challenges for practice, theory and policy. London: Palgrave Macmillan.

Chatman, J. A., \& Jehn, K. A. (1994). Assessing the relationship between industry characteristics and organizational culture: How different can you be? Academy of Management Journal, 37(3), 522-553.

citizen IBM. (2012). Smarter cities challenge: Nairobi, Kenya. Youtube. https:// www.youtube.com/watch?v=xf1H8dQ2ZB4. Accessed 12 Dec 2015.

Clement, R. W. (1994). Culture, leadership, and power: The keys to organizational change. Business Horizons, 37(1), 33-39.

CNBC Africa. (2012). Kresten Buch - Founder of $88 \mathrm{mph}$-Part 1. Youtube. https://www.youtube.com/watch?v=qV5qB4AmME8. Accessed 1 July 2015.

Dartington, T. (1998). From altruism to action: Primary task and the not-forprofit organization. Human Relations, 51(12), 1477-1493.

Deshpandé, R., Farley, J. U., \& Webster Jr., F. E. (1993). Corporate culture, customer orientation, and innovativeness in Japanese firms: A quadrad analysis. The Journal of Marketing, 57(1), 23-37.

Doherty, B., Haugh, H., \& Lyon, F. (2014). Social enterprises as hybrid organizations: A review and research agenda. International Journal of Management Reviews, 16(4), 417-436. 
Duarte. (2012). Erik Hersman Interview with Michael Duarte. Duarte. http:// www.duarte.com/blog/interview-erik-hersman-ted-fellow-founder-of-ihub/. Accessed 22 Mar 2015.

Gichuru, S. (2014). Before anybody convinces you that NGOs are messing up the tech ecosystem. http://www.samgichuru.com/before-anybody-convinces-youthat-ngos-are-messing-up-the-tech-ecosystem/. Accessed 23 June 2015.

Gillespie, T. (2010). The politics of "platforms". New Media \& Society, 12(3), 347-364.

Greenwood, R., \& Hinings, C. R. (1993). Understanding strategic change: The contribution of archetypes. Academy of Management Journal, 36(5), 1052-1081.

Gregory, K. L. (1983). Native-view paradigms: Multiple cultures and culture conflicts in organizations. Administrative Science Quarterly, 28(3), 359-376.

Gupta, S., Beninger, S., \& Ganesh, J. (2015). A hybrid approach to innovation by social enterprises: Lessons from Africa. Social Enterprise Journal, 11(1), 89-112.

Hatcher, J. (2014). Hype around NGO-funded apps is stifling Africa's innovation. Wired UK. http://www.wired.co.uk/news/archive/2014-06/10/siliconsavannah. Accessed 23 June 2015.

Hersman, E. (2014). Builders and talkers: The fallacy of the grant vs investment debate. White African. http://whiteafrican.com/2014/06/18/builders-vstalkers-the-fallacy-of-the-grant-vs-investment-debate/. Accessed 16 Dec 2015. Hull, C. E., \& Lio, B. H. (2006). Innovation in non-profit and for-profit organizations: Visionary, strategic, and financial considerations. Journal of Change Management, 6(1), 53-65.

Hwang, H., \& Powell, W. W. (2009). The rationalization of charity: The influences of professionalism in the nonprofit sector. Administrative Science Quarterly, 54(2), 268-298.

Design Indaba. (2014). Inside Kenya’s iHub. Youtube. https://www.youtube. com/watch?v=iVESsquYn64. Accessed 18 July 2015.

Jaeger, A. M. (1983). The transfer of organizational culture overseas: An approach to control in the multinational corporation. Journal of International Business Studies, 14(2), 91-114.

Kraidy, M. (2005). Hybridity, or the cultural logic of globalization. Philadelphia: Temple University Press.

Lindenberg, M. (2001). Are we at the cutting edge or the blunt edge?: Improving NGO organizational performance with private and public sector strategic management frameworks. Nonprofit Management and Leadership, 11(3), 247-270. 
Mangen, C., \& Brivot, M. (2014). The challenge of sustaining organizational hybridity: The role of power and agency. Human Relations, 68(4), 659-684. Mulupi, D. (2012). Are social impact innovations distracting Kenya from real business? How We Made It In Africa. http://www.howwemadeitinafrica.com/ are-social-impact-innovations-distracting-kenya-from-real-business/15968/. Accessed 15 Dec 2015.

Murta, M. S. (2011). Exploring organizational culture and leadership styles in El Paso nonprofit organizations. ETD collection for University of Texas, Paper AAI1503739.

Njiru, T. (2014). $88 \mathrm{Mph}$ on the ideal space. Youtube. https://www.youtube. com/watch?v=XWcHiRaVNrY. Accessed 12 Dec 2015.

Ogbonna, E., \& Harris, L. C. (2000). Leadership style, organizational culture and performance: Empirical evidence from UK companies. International Journal of Human Resource Management, 11(4), 766-788.

Pettigrew, A. M. (1979). On studying organizational cultures. Administrative Science Quarterly, 24(4), 570-581.

Runciman, W. G. (2005). Culture does evolve. History and Theory, 44(1), 1-13. Schein, E. H. (1990). Organizational culture. American Psychologist, 45(2), 109-119.

Schein, E. H. (2010). Organizational culture and leadership (2nd ed.). New Jersey: John Wiley and Sons.

Tierney, W. G. (1988). Organizational culture in higher education: Defining the essentials. The Journal of Higher Education, 59(1), 2-21.

Watkins, S. C., Swidler, A., \& Hannan, T. (2012). Outsourcing social transformation: Development NGOs as organizations. Annual Review of Sociology, $38(1), 285-315$.

Zahra, S. A. (2003). International expansion of US manufacturing family businesses: The effect of ownership and involvement. Journal of Business Venturing, $18(4), 495-512$. 


\section{Conversation \#10}

\section{Reflections on the Hiring Process: What Happened to Curiosity and Passion?}

\section{Conrad Akunga of Innova Limited}

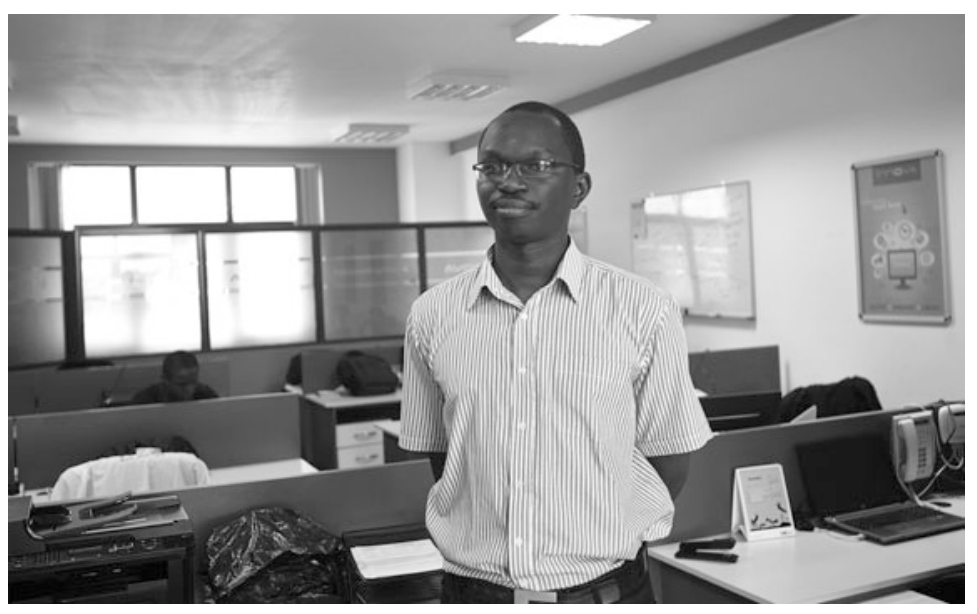

Conrad Akunga is an enthusiastic, optimistic cynic, thinker, developer, son of Kenya, and all-round good guy with a keen interest in governance, economics, technology, and human nature. He has worked with technology for more than 15 years and does not see that changing in the immediate future. He is a cofounder of several initiatives, the main ones being Innova Limited, a pan-African software company that develops analytics and tools for the investment and capital markets, and www.mzalendo.com, a digital governance platform that provides nonpartisan insights into Kenya's government and administration. 


\section{Why did you start Innova, and what is the story behind it?}

Before I started Innova, I worked for a software company that developed supply chain software solutions for almost ten years. We developed clientserver applications running on mobile devices before there was Android. Before there was iOS. Before there was even 3G. Or Edge. It got to the point where I felt I knew the space and the issues like the back of my hand. In that capacity, I led a team that won the 2011 Growth Economy Venture Challenge, a million-dollar award from Nokia. But over time, I grew bored working in a space I knew so well and wanted a new challenge. So I partnered with my longtime friend Vincent Ntalami and went into a space I knew nothing about-finance and capital markets. We started officially in 2011, developing a range of financial software and tools for the capital markets. Today, we have 20 full-time staff, and we develop solutions for custodians, fund managers, private equity firms, and insurance and pension managers. We have clients in five countries—Kenya, Tanzania, Uganda, Zambia, and Malawi.

\section{Entrepreneurship in Africa is quite hyped at the moment. How do you see this development?}

I feel it is unfortunate. Entrepreneurship is considerably romanticized and glorified. Nothing is hotter and sexier than entrepreneurship. The current ethos is that entrepreneurship is the solution to all our problems. I could not disagree more. I agree that entrepreneurship is important, but entrepreneurship is not the Holy Grail or the solution to all our problems. We cannot all be employers. We also need employees. As a matter of fact, employers and employees exist for the exact same reasons. Take the parallel of the armed forces. You cannot have an army of all generals. You also cannot have an army of all noncommissioned officers. Each element brings something to the table, and the whole is greater than the sum of its parts.

Perhaps this new narrative is a knee-jerk response to the atmosphere we have been brought up in. For generations, kids have been told the following: go to primary school, work hard so you can go to a good secondary school, work hard so you can go to a good university, and finally work hard so you can get a good job. Generations and generations conditioned in this fashion have led to an education system optimized around producing employees, which, in turn, produces graduates who seek jobs. That is the demand side-employment. However, not much used to happen on the supply side-entrepreneurship. Perhaps that is 
why the entrepreneurship narrative is getting such a reaction. It is the complete antithesis of the status quo.

The other issue I feel we have with the education system is its outright bias toward science, technology, engineering, and mathematics (STEM). Do not get me wrong-I think STEM is very important. But I also feel that the humanities, arts, and physical education are just as important. Again our kids have been conditioned to grow up to become doctors and engineers. In Kenya, the exit point from primary school is a nationwide examination called the Kenya Certificate of Primary Education. Millions of students appear for this exam around November, and by January, the results are out. There is generally much fanfare, and the highest-scoring students are identified, celebrated, and interviewed. And every year, without fail, these kids are asked what they want to be when they are done with education. They invariably respond with some variation on doctor, surgeon, engineer. I cannot recall ever hearing any of these kids say they want to be poets or dancers or artists. In our schools, a smart kid is one who is good at math or science; a kid who is good at drawing, curiously, is referred to as "talented." But not smart. For society as a whole to flourish, each of these disciplines brings something to the table. We need STEM. But we also need arts. And physical sciences. And humanities. A holistic approach to our development capacity.

\section{How will more "curious" students graduate from the education system?}

I have always felt that the really good teachers can only be truly recognized after they have left their students to themselves. Allow me to explain what I mean by that. Given that our education system is optimized around passing exams, anyone with a good memory can cram facts and dates and regurgitate them at exam time. But knowing facts and understanding and internalizing them is a different kettle of fish. Good teachers plant a seed in your head, and usually you are blissfully unaware of it. They instil curiosity. Curiosity is what will make you go to the library and look for books on how electricity works. Not because there is an exam or because you have been asked to. You have gone on your own because you simply want to know. Things you learn out of curiosity, or genuine passion, stick in your head a lot longer than those bullet points you crammed to pass an exam and almost immediately forgot. This model of a teacher standing in front, rapping out notes, and then students regurgitating the same notes back at them during exams needs to be reviewed. I have interviewed software 
developers and architects for almost 15 years now, and I am simultaneously saddened and amused by the number of graduates, masters, and even postgraduate prospects who have no clue about even the most basic fundamentals of computer science. What then does your degree prove other than that you know how to pass exams? What is it worth if you cannot access what you claim you know? It is a tragedy on so many levels.

\section{How do you filter out job candidates that can apply and not only repeat what they have learned?}

For starters, I no longer care whether anyone has a degree. As a matter of fact, for some positions, a degree paradoxically seems to get in the way. A degree seems to install some kind of thoughts barriers (justified or not), and I want a mindset that either does not realize there are any barriers or ignores them completely. There is a lot to be said for dreamers and the doggedly determined who are not held back by reality.

Just like our education system, the interview process is also broken. Take the usual hiring situation...

INTERVIEWER: Tell us about yourself.

Interviewee: My name is Mary. I am a hard-working, God-fearing citizen.

INTERVIEWER: Tell us about your past jobs.

INTERVIEWEE: Currently I work at....

INTERVIEWER: What are your strengths?

INTERVIEWEE: I am a team player. I work well under pressure. I require minimal supervision.

INTERVIEWER: What are your weaknesses?

INTERVIEWEE: I am a perfectionist.

It is as if there were a universal template-literally dozens of interviews where I have heard the same things. At Innova, we used this model for many years until we had some particularly disastrous hires who interviewed well but not only performed poorly, they but actually retrogressed us. We realized that it is impossible to know if someone will be good at their job during the interview. Some people interview well and flounder. What if there were 
people who interviewed poorly but would have turned out to be exceptional? So we changed it. We use the interview to get to know you, and vice versa. We sell you our vision and expectations. You do the same. Meet our team and your potential colleagues. What are your interests? What are you passionate about? Convince us to give you a chance, not a job. After this, you work for three months. How good are you at the job? Are you a team player? Are you pleasant to work with? Do you enjoy the work? Can you manage yourself and your time? Are you willing to pull together and pitch in during emergencies? We do not enforce official working hours, so these things matter. After these three months, your colleagues and your head of department vote whether to keep you or not. Any negative votes—-no hire. After all, if your colleagues do not want to work with you, how useful can you be in a collective effort? It has worked extremely well for us.

\section{How many people do you find that fit the profile of a creative problem solver?}

It is very difficult to find those, because almost all software developers come with the mindset that their primary work is to write code. This is not true. Their primary work is to understand and solve problems. Writing code just happens to be one of the tools at their disposal. The other problem is that they come in as Java guys. Or $\mathrm{C}++$ guys. Or C\# guys. They do not come in as programmers. The programming language is neither here nor there. What is important is the knowledge and understanding of algorithms and data structures. Syntax and organization of source code is a book or a google away. Mindset and attitude are the most important things. Are you curious? Determined? Passionate? Driven? If so, most of the war is won. The technical stuff we can teach you. However, we cannot teach you the former. My old boss Francis Kioko once told me that the first thing you should do when you take on a new job or opportunity is to train your replacement. At the time, that made no sense to me, because it sounded like career suicide. But with age came wisdom, and I understood that much as I could try to impart all of my technical knowledge, what I could not impart, even if I wanted to, was my experience- how to apply said knowledge: That is your edge! You cannot study this by cramming and repeating what you have read. You need to start trying and learning by applying knowledge. We are looking for those who know how to put their knowledge to work. 


\section{Hustling is very prominent in Kenya. What is your opinion on the "hustling" entrepreneur?}

It depends. If hustling is a temporary and reactionary move, in exceptional circumstances, then it makes sense. If it is the end of the month and you do not have the cash flow for payroll, how can you temporarily address that situation? Aggressive negotiation? Overdraft? Short-term consultancy? If, however, hustling is your standard mode of operation, then you have a big problem. It is not sustainable or scalable. You will be spread too thin. You will not be focused. And that is bad for you, your employees, and your company. Here, hustling is a bad thing. Structure, planning, and process are essential for scaling and growth. The dubious badge of honour carried by those who are permanent hustlers needs to be retired. If you are constantly hustling, you have fundamental problems. Fix them.

\section{Let us imagine you could start Innova all over again. What would you change?}

I have been asked this several times, and I used to answer, "I should have started sooner." But again, with age comes wisdom. If I had started sooner, would I have had the experiences and lessons that shaped my thinking and attitude today? Because learning includes both the things you should do and the things you should not. All of these played a part to make me who I am today. And so I can answer confidently that, with hindsight, I would not change a thing!

\section{Thank you, Conrad!}

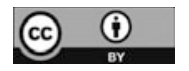
to the original author(s) and the source, provide a link to the Creative Commons license and indicate if changes were made.

The images or other third party material in this chapter are included in the work's Creative Commons license, unless indicated otherwise in the credit line; if such material is not included in the work's Creative Commons license and the respective action is not permitted by statutory regulation, users will need to obtain permission from the license holder to duplicate, adapt or reproduce the material. 